\title{
Decreased Choroidal Blood Flow Associated with Retinitis Pigmentosa
}

\author{
MAURICE E. LANGHAM and THERESA KRAMER* \\ Baltimore and Georgia, USA
}

\begin{abstract}
Summary
The intraocular pressure pulse has been measured and used to evaluate the ophthalmic arterial pressure and the ocular pulsatile blood flow in 13 retinitis pigmentosa patients and ten similar aged healthy volunteers. The light sensitivity thresholds of the central fields of all persons were recorded using the Heijl-Krakau automated perimeter. The mean pulse amplitudes of $1.2 \pm 0.2(26)$ and $2.3 \pm 0.25(20) \mathrm{mmHg}$ in the affected and in the control groups respectively differed significantly $(p<0.001)$. The corresponding pulsatile blood flows were $310 \pm 24(26)$ and $628 \pm 40$ (20) $\mu \mathrm{l} \mathrm{min}^{-1}$. The mean ophthalmic arterial pressures in the two groups were equal. The light sensitivities in pairs of eyes of four of the patients differed substantially and in all cases the eye with the better visual performance had the higher ocular pulsatile blood flow. It is concluded that relative choroidal ischaemia is closely associated with visual loss and pigment cell degeneration in patients with retinitis pigmentosa.
\end{abstract}

Retinitis pigmentosa (RP) is a degenerative disease of the retinal neuroepithelium, characterised by progressive loss of photoreceptors. Clinically, it is frequently associated with a narrowing of the retinal vessels, atrophy of the optic nerve, and pigmentary changes in the retina.

Circulatory changes have been observed to occur in the retina and choroid of RP patients but it has remained unclear whether these play a role in the pathogenesis of this disease (for review see Merin and Auerbach 1977). Attenuation of retinal vessels has been observed and a sclerosis and atrophy of the chorio-capillaris documented in RP patients. ${ }^{1,2,3}$ In vivo, the results of fluorescein angiography have indicated choroidal vessel pathology both in the early and late stages of the disease..$^{4,5,6}$ However, Verhoef ${ }^{8}$ and
Cogan ${ }^{9}$ reported minimal choroidal sclerosis and questionable deterioration of the choriocapillaris in eight cases of severe RP. Best, Toyofuka and Galin $^{10}$ reported that some patients with long-term disease had normal fluorescein retinal transit times and apparently normal fluorescein filling of the choroid; they concluded that ocular haemodynamics plays no role in the pathogenesis of the disease.

The aim of the present study has been to determine whether the ocular haemodynamics in the RP patient is abnormal and if so whether the changes occur in the early or in the late stages of the disease. Specifically, the ophthalmic arterial pressure (OAP), the ocular pulsatile blood flow (PBF) and the total blood flow have been evaluated. The OAP has been derived from the relation between the intraocular pressure (IOP) and

From: The Ocular Pharmacology and Therapeutics Unit, The Johns Hopkins University School of Medicine and *The Department of Ophthalmology, Emory University, Georgia.

Correspondence to: Maurice E. Langham, The Wilmer Institute, Woods Research 255, The Johns Hopkins University School of Medicine, 601 North Broadway Baltimore, Maryland 21205, USA. 
Table I The visual acuities and the inheritance patterns in the patients with pigmentary retinal degeneration

\begin{tabular}{rccccc}
\hline & \multicolumn{2}{c}{ Patient } & \multicolumn{2}{c}{ Visual Acuities } & $\begin{array}{c}\text { Retinitis Pigmentosa } \\
\text { Inheritance Pattern }\end{array}$ \\
\hline 1 & Race/Sex & Age & O.D. & O.S. & Simplex \\
2 & BM & 38 & $20 / 60$ & $20 / 50$ & Simplex \\
3 & WF & 63 & $20 / 60$ & $20 / 60$ & Simplex \\
4 & WM & 23 & $20 / 50$ & $20 / 40$ & Simplex \\
5 & WF & 18 & $20 / 25$ & $20 / 25$ & $\begin{array}{c}\text { Autosomal recessive } \\
\text { or X-linked }\end{array}$ \\
& WM & 56 & $20 / 50$ & $20 / 60$ & $\begin{array}{c}\text { Probable autosomal } \\
\text { dominant }\end{array}$ \\
6 & & & & & Autosomal recessive \\
& WM & 36 & $20 / 20$ & $20 / 20$ & or X-linked \\
& & & & & Autosomal recessive \\
8 & WM & 34 & Hand & Hand & Simplex \\
& & & motions & motions & Simplex \\
9 & WF & 38 & $20 / 16$ & $20 / 16$ & Simplex \\
10 & & & $20 / 16$ & $20 / 25$ & Simplex \\
11 & BF & 37 & $20 / 16$ & $20 / 30$ & Simplex \\
12 & WM & 21 & $20 / 16$ & $20 / 30$ & $20 / 16$ \\
13 & WM & 30 & $20 / 25$ & & \\
\hline
\end{tabular}

the pulse amplitude (PA). ${ }^{11,12,13}$ The PBF has been evaluated from analysis of the IOP pulse as described by Silver et al. ${ }^{14}$

\section{Materials and Methods}

Thirteen patients diagnosed as typical RP were referred from the Retinitis Pigmentosa Center of The Wilmer Eye Institute. The clinical findings on these patients are summarised in Table I. The diagnosis of RP was based on the presence of night blindness, visual acuity exceeding $20 / 30$ until late in the disease, intra-retinal mid-peripheral 'bone corpuscular' pigmentation, narrowed retinal arteries, ring scotoma and/or visual field constriction, vitreous degeneration with pigment dusting and diminished or abolished electroretinograms. The group comprised seven men (34 \pm 4.4 years; range $21-56$ years) and six females ( $39 \pm 5.7$ years; range $18-63$ years). The 10 control subjects were volunteers with no history of ocular or chronic systemic disease. All control subjects received an ocular examination prior to the study. The group comprised four females (37.5 \pm 5 years; range 20-56 years) and six males (39 \pm 4 years; range $20-61$ years).

\section{Analytical Methods}

The Heijl-Krakau automated flat screen peri- meter was used for all visual threshold measurements. ${ }^{15,16}$ The test field comprised 64 light emitting diodes forming a circular pattern covering the central $20^{\circ}$ of vision (Fig. 1). Sixteen light intensity levels ranging from a zero level (the highest intensity 10000 asb, i.e. $318 \mathrm{~cd} / \mathrm{m}^{2}$ ) to the 16 th level (the lowest intensity $0.03 \mathrm{asb}$ ). The exposure time of the light stimulus was $0.25 \mathrm{sec}$ unless otherwise stated. The intra-stimulus time was two sec when the patient did not respond, but when the patient responded the following light stimulus was initiated $0.5 \mathrm{sec}$ later. Visual fixation was checked by random exposures on the blind spot at an approximate frequency of one in nine threshold determinations. Background illumination comprised eight low-voltage lamps to give a screen luminance of $1 \mathrm{~cd} / \mathrm{m}^{2}$.

The IOP was recorded with the Langham pneumatic tonometer using a modified BioRad OCVM system (Digilab Medical Division, Cambridge, MA). The system was calibrated for the steady state IOP and for the dynamic pulse response by manometric studies on enucleated eyes. Analogue recordings of the IOP were made using a pen writer with a sensitivity of $5 \mathrm{~mm}$ displacement for a pressure of $1 \mathrm{mmHg}$. Evaluation of the PBF was made from the pulse recording using the mathematical method described by Silver $e t$ $a l{ }^{14}$ The OAP was evaluated using the procedure of Langham and To'mey. ${ }^{11}$ In brief, the IOP and the IOP pulse were recorded at a 


\section{RIGII'T}

\section{BLINJ) SPU'I}

EXP 18 SEEN 5 o

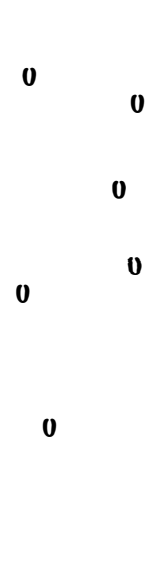

0

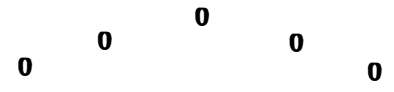

o

o

o<smiles>[13CH3]</smiles>

o

o

o

o 0

o 0

1

$\begin{array}{ll}3 & -1 \\ 0 & \end{array}$<smiles>I[Tl]</smiles>

$\mathbf{0}$

1,11

10

$-1$

o 0

o

$-1$

$\mathbf{0} 3$

o

o

$\begin{array}{lll}0 & & 0\end{array}$

o

PERFORMANCE $=520$

I,EFT

BISIND SPO'T

I:XP 27 SEEN $O$

1) 37

12

23

$3 \quad 8$

12

50

6 2

70

80

9 0

110

120

130

110

15

$Q=1$

PERPORMANCE $=92$

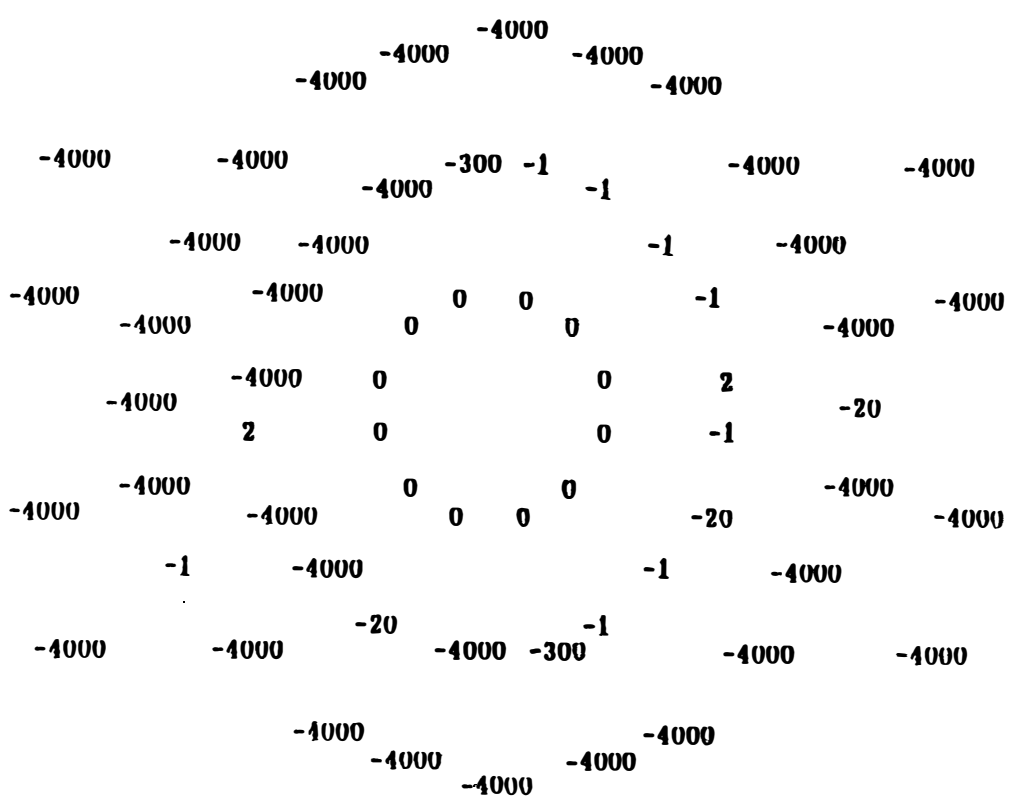

Fig. 1. The recordings of the lightsensitivity thresholds in the left (upper figure) and the right (lower figure) eyes of a white male aged 34 with RP (patient No 7 Table I). The first column on the left records the 16 levels of light intensity and the second column records the number of retinal points having the same light sensitivity thresholds. The number of times the blind spot was illuminated and the number of times the patient responded are given above column 1. $Q$ is the modal value of the light sensitivity thresholds. The circular pattern shows the 64 retinal points tested. Points with light sensitivities equal to the modal value are shown as zeros. Points with thresholds below or above the modal value are given negative or positive values respectively according to the number of steps from the modal value. Zeros are added to the negative values to underscore the areas of relative visual loss. The visual performance is the sum of the product of the number of responses at each intensity level. 


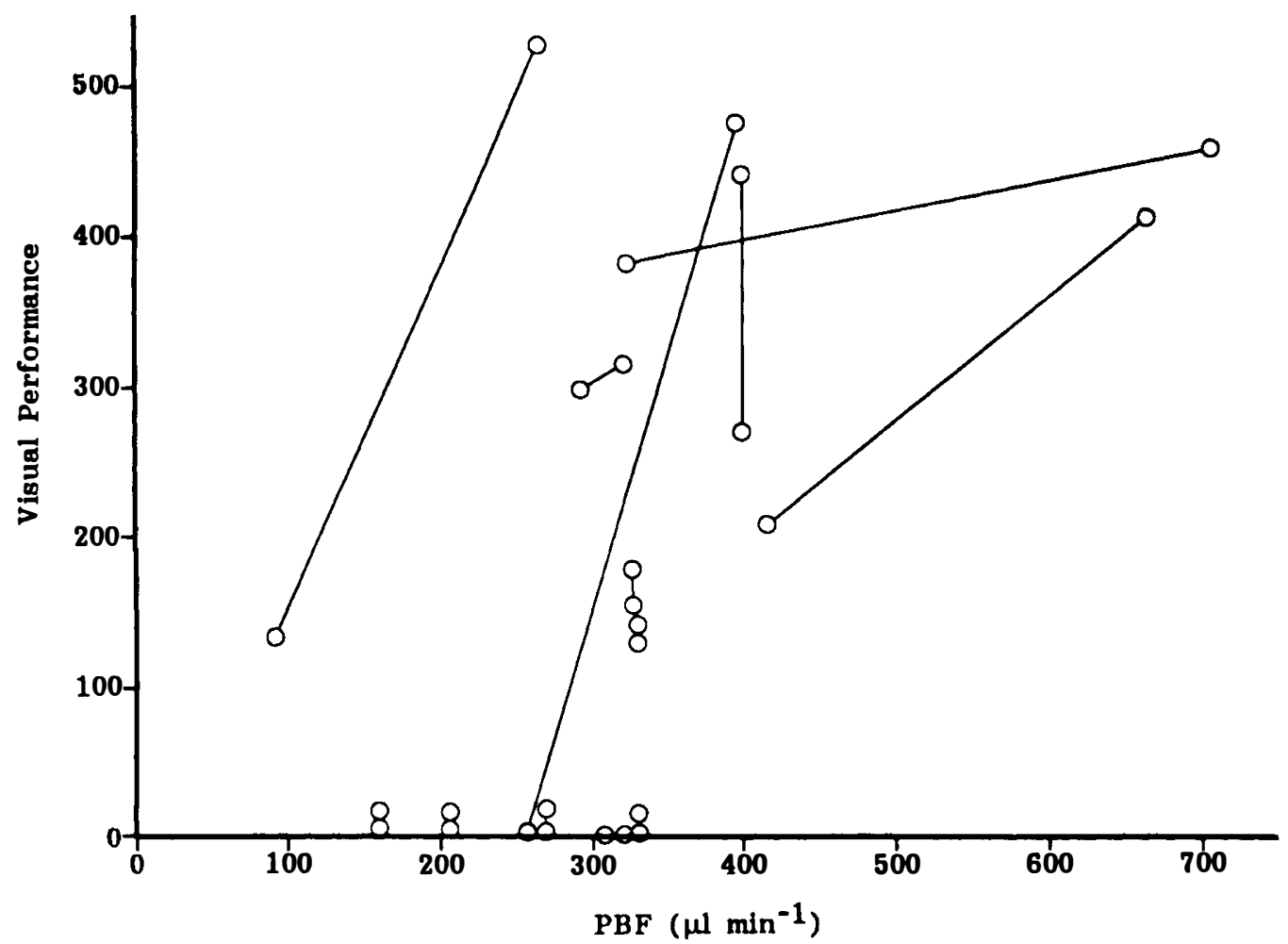

Fig. 2. The relation between the visual performance and PBF in pairs of eyes of individual RP patients. The corresponding values for the control subjects were $734 \pm 25$ (20) and $628 \pm 40$ (20) $\mu \mathrm{l} \mathrm{min}$ for $^{-1}$ the visual performance and the PBF respectively. The lines connect results in pairs of eyes of individual patients.

series of increasing pressures until the pulse approached close to or equalled zero amplitude. The individual values were then plotted to give the IOP/PA relation; the ophthalmic systolic pressure is the IOP at which the PA becomes zero. The ophthalmic diastolic pressure in individual eyes was taken to be equal to a factor $\mathrm{E}$ times the brachial arterial diastolic pressure, where $E$ is the ratio of the systolic OAP to the brachial arterial systolic pressure. This calculation is based on data of Galin, Baras, Cavero and Best ${ }^{17}$ that the ratios of the diastolic and systolic OAPs to the corresponding brachial pressures were identical in human subjects. The outflow facility was measured by the pneumatonographic procedure using the Digilab OCVM. ${ }^{18}$ The rate of aqueous humour formation was calculated from the flow equation $F=C\left(P_{o}-P_{v}\right)$, where $C$ is the outflow facility, $P_{o}$ is the IOP and $P_{v}$ is the recipient venous pressure. The coefficient of ocular rigidity was evaluated from the values of $P_{o}$ and $P_{t}$, where $P_{t}$ is the IOP induced by the addition of a $10 \mathrm{~g}$ weight to the tonometric sensor. ${ }^{18}$ No significant difference was found between the coefficients of ocular rigidity between the RP $\left(0.0190 \pm 0002 \mu \mathrm{l}^{-1}\right)$ and control subjects $\left(0.020 \pm 0.0002 \mu \mathrm{l}^{-1}\right)$.

Results are expressed as the arithmetic mean \pm the standard of the mean. The number of eyes studied are given in parenthesis. Comparison of the means were made using the Student $t$ test.

\section{Results}

In the eyes of the RP patients the mean PA and the mean diastolic IOP were $1.2 \pm 0.6$ (26) $\mathrm{mmHg}$ and $14.1 \pm 0.15$ (26) $\mathrm{mmHg}$ respectively. In the control group the $\mathrm{PA}$ was $2.6 \pm 0.5(20) \mathrm{mmHg}$ and the diastolic IOP $15.4 \pm 0.2$ (20) $\mathrm{mmHg}$; the difference between the two PA means was significant $(\mathrm{p}<0.001)$. 


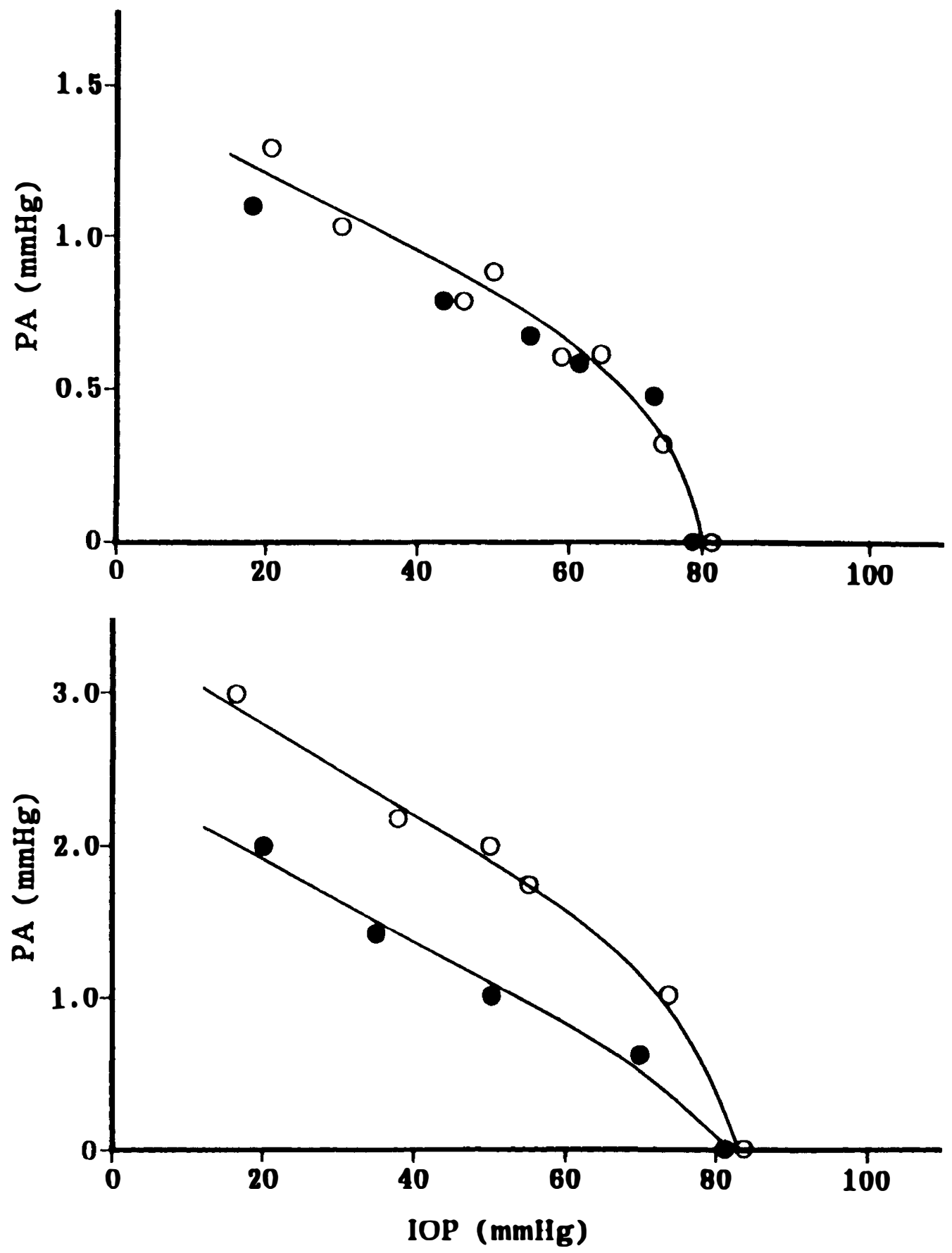

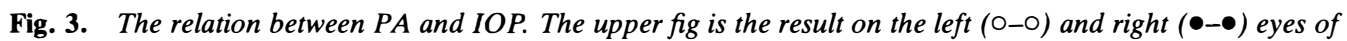
patient No 6 (Table I) The lower fig is the result on the left $(0-0)$ and the right $(\bullet-\bullet)$ eyes of patient No 10 (Table I).

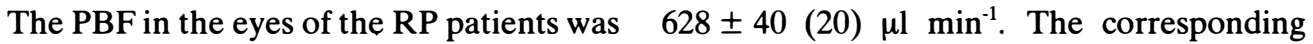
$310 \pm 24(26) \mu l \mathrm{~min}^{-1}$ and in the control group visual performances in the RP and control 
groups were $125 \pm 50(26)$ and $734 \pm 25$ (20) respectively.

Figure 2 summarises the relation between the PBF and the visual performance in individual eyes of the RP patients. The central vision in 11 eyes was very poor and the corresponding visual performances were zero. These 11 eyes had a mean PBF of $265 \pm 22 \mu$ min $^{-1}$ which was significantly below the mean PBF in the control group of $628 \pm 40(20) \mu$ $\left.\min ^{-1} \mathrm{p}<0.001\right)$. The remaining 15 eyes had positive visual performances $(435 \pm 20)$ and a mean PBF of $385 \pm 50 \mu \mathrm{l} \mathrm{min}{ }^{-1}$ which was also significantly below the mean PBF of the control group $(\mathrm{p}<0.001)$. The mean PBFs in the two RP groups differed significantly $(p<0.01)$. The PBF in the individual eyes of the 15 eyes with positive visual performances were all less than the mean of the control group. Five patients had asymmetry of light sensitivity thresholds and the eyes with the higher visual performances also had the greater PBFs; in the fifth case the PBFs in the two eyes were equal. Fundus examination in these subjects revealed symmetrical findings.

The low PA values in the eyes of RP patients relative to eyes of healthy subjects persisted when the IOP was increased. Figure 3 shows representative results of the PAs at increased IOPs in two of the RP patients. Figure $3 \mathrm{a}$ shows the results on a male patient aged 36 years (Table I No 6). He has visual performances of 154 and 177 in the left and right eyes respectively and PBFs of $333 \mu \mathrm{l}$ $\mathrm{min}^{-1}$ in the two eyes. The symmetry of the $\mathrm{PA} / \mathrm{IOP}$ relations in the eyes of this patient was present in 10 of the 13 patients. In the three remaining cases the PAs differed between the two eyes of individual patients and the asymmetry persisted as the IOP was increased. A representative example of this asymmetry in a male of 21 years is shown in Fig $3 b$ (Table I No 10). His visual performances were 464 and 385 in the left and right eyes respectively. Both values are well below the mean of 734 in the control eyes. The PAs remained asymmetric as the IOP was increased but the OAPs in pairs of eyes were equal. The PBFs in the undisturbed eyes were 710 and $325 \mu 1 \mathrm{~min}^{-1}$ respectively.

The mean OAP in the RP patients was $82.8 \pm 3.7(26) \mathrm{mmHg}$ and the brachial artery systolic blood pressure (BrAP) $115 \pm 4$ (13) $\mathrm{mmHg}$. The ratio $\mathrm{OAP} / \mathrm{BrAP}$ in individual $\mathrm{RP}$ eyes was $0.69 \pm 0.04$ (26). This value is almost identical to the mean OAP/BrAP ratio of $0.67 \pm 0.03$ in the control group and to the value of $0.69 \pm 0.01$ reported previously in a series of 20 healthy young adults. ${ }^{11}$ The mean OAP and the corresponding BrAP in the control subjects were $83.4 \pm 3(20) \mathrm{mmHg}$ and $123 \pm 5(10) \mathrm{mmHg}$ respectively.

The PBF at the diastolic OAP was $123 \pm 20$ (26) $\mu \mathrm{l} \mathrm{min} \mathrm{m}^{-1}$ in the RP patients and $264 \pm 18$ (20) $\mu \mathrm{l} \mathrm{min}^{-1}$ in the control group.

The possibility that the abnormally low PBF in the RP patients was associated with a decreased rate of aqueous humour formation (F) was evaluated from the coefficient of outflow facility $(C)$ and the IOP. The mean values of $\mathrm{C}$ and $\mathrm{F}$ in the eyes of the RP patients was $0.24 \pm 0.04(26) \quad \mu \mathrm{min}^{-1} \mathrm{mmHg}^{-1} \quad$ and $1.1 \pm 0.2(26) \mu \mathrm{l} \mathrm{min}^{-1}$ respectively. In the control subjects the mean values of $C$ and $F$ were $0.28 \pm 0.03$ (20) $\mu \mathrm{l} \mathrm{min}^{-1} \mathrm{mmHg}^{-1}$ and $2.3 \pm 0.2(20) \mu l \mathrm{~min}^{-1}$ respectively.

\section{Discussion}

The mean PA in the eyes of the RP patients was significantly less than in the control eyes and provides evidence of a corresponding abnormally low PBF.

The mean decrease of approximately $400 \mu \mathrm{l}$ min $^{-1}$ PBF in the RP patients far exceeds the total retinal blood flow and therefore must have occurred predominantly in the ciliary choroidal vessels which receive $90-95 \%$ of the total ocular blood flow. In healthy human eyes the total volumetric blood flow in the retina has been reported to be $33 \pm 9.6 \mu \mathrm{l} \mathrm{min}{ }^{-1,19}$ and $80 \pm 12 \mu \mathrm{l} \mathrm{min}^{-1,20}$ based on laser doppler velocimetry. ${ }^{21,22}$ The total ocular blood flow in man remains uncertain. Using an indirect method van Beuningen and Fischer ${ }^{23}$ reported a mean value of $1000 \mu \mathrm{l} \mathrm{min}{ }^{-1}$. A similar value of $1000 \mu \mathrm{l} \mathrm{min} \mathrm{m}^{-1}$ for conscious rabbits was reported by $\mathrm{Bill}^{24}$ using a radioactively labelled microsphere entrapment technique. The same technology has established the choroidal blood flow in the primate to be 20-25 times that of the retina. ${ }^{25,26,27}$

The possibility that the decreased PBF reflected a similar decrease in total ocular blood flow is supported by the persistence of 
abnormally low PBF at IOPs equal to and exceeding the ophthalmic diastolic pressure. At this pressure, entry of blood into the eye can occur only during the systolic phase of the cardiac cycle. This means that the non-pulsatile component is zero at this pressure and the remaining PBF is the total blood flow. The $\mathrm{PBF}$ at the diastolic OAP in the RP patients was approximately one half of that in the eyes of normal subjects.

The loss of PBF in the eyes of the RP patients could not have been due to decreased OPP as the OAP in all patients were normal. However, the possibility that loss of PBF was partly due to an increase in the non-pulsatile blood flow cannot be excluded.

The presence of relative choroidal ischaemia is in keeping with the frequently reported sclerosis of the choroidal vessels in RP patients. It may also explain the pattern of visual loss in this disease. Historically, the concept of a defective blood supply was proposed to account for the initial visual loss that frequently causes a ring scotoma in the equatorial region of RP patients. ${ }^{1,2}$ This is the same area of the retina that vision is first lost in normal eyes when the blood flow is reduced by raising the IOP (see Ref. 11). Parri passu, the last stages of visual loss in the RP eye occurs in the macular, which is adjacent to a dense network of retinal capillaries ${ }^{28}$ and to the region of the choriocapillaris fed by arterial blood at maximal perfusion pressure from the short posterior ciliary arteries.

The extent to which the decrease in PBF contributes to the degenerative changes in the pigment epithelium and the photoreceptors remains to be resolved. Feke, Zuckerman, Green and Weiter ${ }^{29}$ calculated that in normal subjects the retinal blood flow could supply $30 \%$ of the oxygen utilised by the retina, leaving the remaining $70 \%$ to be supplied by the ciliary choroidal vessels. The same investigators also observed that the retinal blood flow increased by $40-70 \%$ in the dark, thereby providing extra oxygen needed by the photoreceptors to regenerate visual pigments. Loss of ocular blood flow decreases the oxygen tension in the retina,,$^{30}$ and this will be more severe in the region immediately adjacent to the segment of the photoreceptors densely packed with mitochondria. ${ }^{31}$
In view of the observations that substantial loss of PBF was found in eyes of RP patients with partial visual loss, it would be logical to evaluate the therapeutic action of increased ocular blood flow on the course of retinal degeneration in RP patients that have not yet suffered severe visual loss. This rationale is supported by the observation that in individual patients the loss of blood flow was greatest in the eye with the poorer visual performance. The therapy of increased ocular blood flow was investigated in the past with little long term success (see Ref. 3). However, at the time these circulatory studies were made there were few, if any, therapeutic methods for sustaining increased ocular blood flow. A re-evaluation of this therapeutic possibility would appear to be timely in view of availability in recent years of drugs that increase ocular blood flow.

We are indebted to the Retinitis Center of The Wilmer Ophthalmological Institute for referring the patients presented in this study and for their encouragement to undertake the investigation.

\section{References}

${ }^{1}$ Gonin J: Examen anatomique d'un oeil atteint de retinite pigmentaire en voie d'evalution avec scotome zonulaire. Ann Oculist 1903, 128: 401-419.

${ }^{2}$ Hepburn ML: Discussion of retinitis pigmentosa. Trans Ophthalmol Soc UK 1938, 58: 246-55.

${ }^{3}$ Duke-Elder S and Dobree J: System of Ophthalmology Volume X: Diseases of the Retina. St. Louis, C. V. Mosby, 1967: pp 577.

${ }^{4}$ Hyvarinen L, Maumenee AE, George T: Fluorescein angiography of the choriocapillaris. Am J Ophthalmol 1969, 67, 653-66.

${ }^{5}$ Krill AE, Archer D, Newell FW: Fluorescein angiography in retinitis pigmentosa. $\mathrm{Am} \mathrm{J} \mathrm{Oph-}$ thalmol 1970, 69: 826-35.

${ }^{6}$ Weinstein GW, Maumenee AE, Hyvarinen L: On the pathogenesis of retinitis pigmentosa. Ophthalmologica 1971, 65: 82-97.

${ }^{7}$ Merin S and Auerbach E: Retinitis Pigmentosa Review. Surv Ophthalmol 1976, 20: 303-46.

${ }^{8}$ Verhoeff FH: Microscopic observations in a case of retinitis pigmentosa. Arch Ophthalmol 1931, 5: 392-407.

${ }^{9}$ Cogan DG: Pathology in Symposium: Primary choreoretinal aberrations with night blindness. Trans Am Acad Ophthalmol Otolaryng 1950, 54: 629-61.

${ }^{10}$ Best M, Toyofuku H, Galin MA: Ocular hemodynamics in retinitis pigmentosa. Arch Ophthalmol 1972, 88: 124-30.

${ }^{11}$ Langham ME and To'mey KF: A clinical procedure for the measurement of ocular pulse-pressure relationship and the ophthalmic arterial pressure. Exp Eye Res (1978), 27: 17-25. 
${ }^{12}$ Langham ME, To'mey KF, Preziosi T: Carotid occlusive disease: The effect of complete occlusion of the internal carotid artery on the intraocular pulse/pressure. Stroke 1981, 12: 759-65.

${ }^{13}$ Langham ME and Preziosi T: Non-invasive diagnosis of mild to severe stenosis of the internal carotid artery. Stroke 1984, 16: 614-20.

${ }^{14}$ Silver DA, Farrell RA, Langham ME, O'Brien V, Schilder P: Estimation of pulsatile ocular blood flow from intraocular pressure. Acta Ophthalmol 1989, (Supplement) 191: 67: 25-29.

${ }^{15}$ Heijl A and Krakau CET: An automatic static perimeter, design and pilot study. Acta Ophthalmol 1975, 53: 293-310.

${ }^{16}$ Krakau CET: Aspects of the design of an automatic perimeter. Acta Ophthalmol (Copenhagen) 1978, 56: $389-405$.

${ }^{17}$ Galin MA, Baris I, Cavero R, Best M: Compression and suction ophthalmodynamometry. Am J Ophthalmol 1969, 67: 388-92.

${ }^{18}$ Langham ME, Leydecker W, Kreiglestein G, Waller W: Clinical evaluation of a new methodology in the diagnosis of glaucoma. Adv Ophthalmol 1976, 32: 108-33.

${ }^{19}$ Riva CE, Grunwald JE, Sinclair SH, Petrig BL: Blood velocity and volumetric flow rate in human retinal vessels. Invest Ophthalmol Vis Sci 1985, 26: 1124-32.

${ }^{20}$ Feke GT, Tagawa H, Deupree DM, Goger DG, Sebag J, Weiter JJ: Blood flow in normal human retina. Invest Ophthalmol Vis Sci 1989, 30: 58-65.

${ }^{21}$ Riva CE and Feke GT: Laser doppler velocity in the measurement of retinal blood flow. In The Biomedical Laser: Technology and clinical applications. Springer-Verlag 1981: 135-61.

${ }^{22}$ Riva CE, Grunwald JE, Sinclair SH, O'Keefe: Fundus camera based retinal LDV. Appl Optics 1981, 20: $117-227$.
${ }^{23}$ van Beunigen EGA and Fischer FW: Die arterielle Minutenvolumenbestimmung des Auges und ihre klinische Bedeutung. Bericht der Deutsche Ophthalmol Gesellschat (Heidelberg) 1957, 61: 218-27.

${ }^{24}$ Bill A: Effects of acetazolamide and carotid occlusionon the ocular blood flow in unanesthetized rabbits. Invest Ophthalmol Vis Sci 1974, 13: 954-58.

${ }^{25}$ O'Day DM, Fish MB, Aronson JB, Pollycove M, Coon A: Ocular blood flow measurement by nuclide labelled microspheres. Arch Ophthalmol 1971, 86: 205-9.

${ }^{26}$ Aim A and Bill A: Ocular and optic nerve blood flow at normal and increased intraocular pressure in monkeys (macaca iris): A study with radioactive labelled microspheres including flow determinations in brain and some other tissues. Exp Eye Res 1973, 15: 15-19.

${ }^{27}$ Alm A, Bill A, Young FA: The effect of pilocarpine and neostigmine on the blood flow through the anterior uvea in monkeys: A study with radioactivity labelled microspheres. Exp Eye Res 1973, 15: $31-6$.

${ }^{28}$ Michaelson IC: In 'Retinal Circulation in Man and Animals'. C. C. Thomas, Springfield, Illinois 1954.

${ }^{29}$ Feke GT, Zuckerman R, Green CJ, Weiter JJ: Response of human retinal blood flow to light and dark. Invest Ophthalmol Vis Sci 1983, 24: 136-41.

${ }^{30}$ Yancey CM and Linsenmeier RA: Oxygen distribution and consumption in the cat retina at increased intraocular pressure. Invest Ophthalmol Vis Sci 1989, 30: 600-18.

${ }^{31}$ Steinberg RH: Monitoring communications between photoreceptors and pigment epithelial cells: Effects of 'mild' systemic hypoxia. Invest Ophthalmol Vis Sci 1987, 28: 1898-904. 